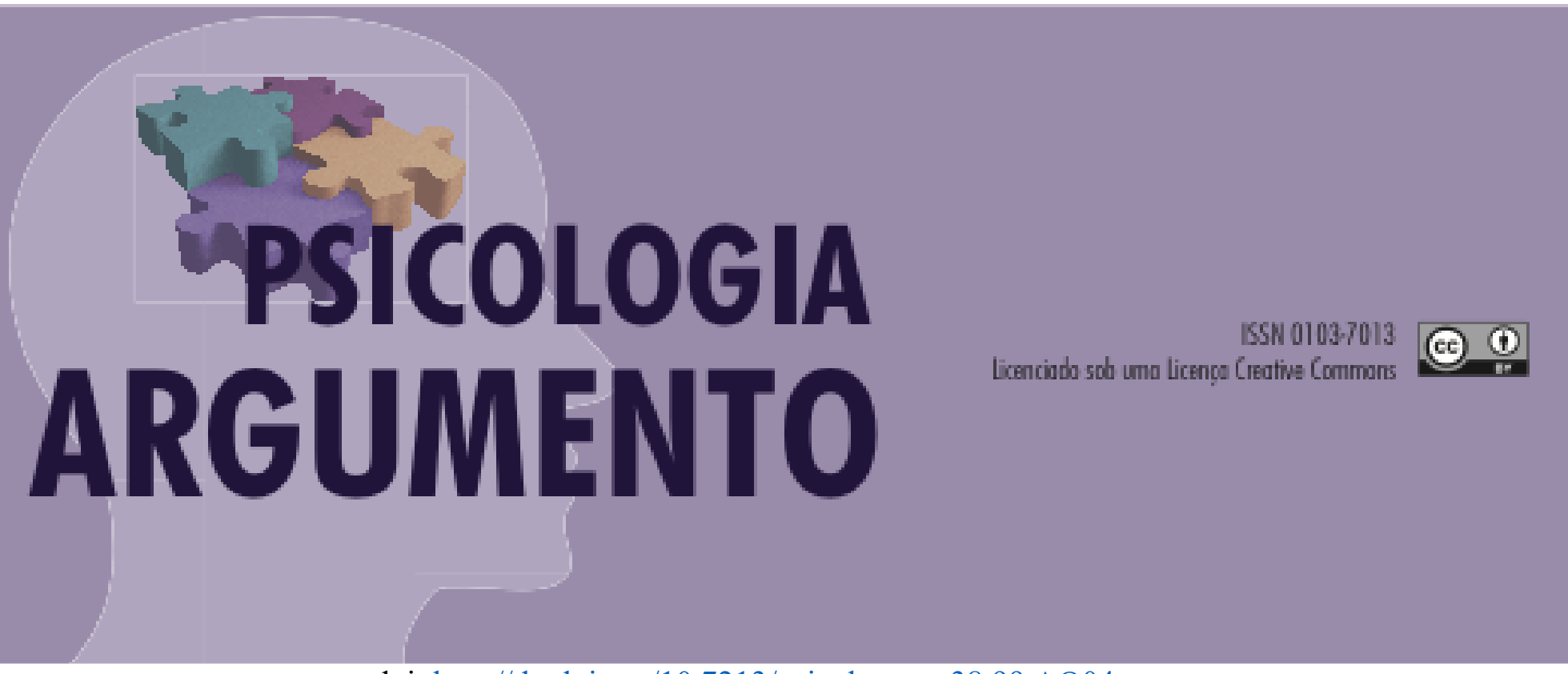

doi: http://dx.doi.org/10.7213/psicolargum.38.99.AO04

\title{
Transformações da identidade feminina ao tornar-se mãe
}

Transformations of female identity by becoming a mother

Transformaciones de identidad femenina al convertirse en madre

Ana Caroline Machado

Universidade de Sorocaba, e-mail: anacarol.machado14@gmail.com,

ORCID: https://orcid.org/0000-0001-5751-2419

Camila Cristine da Silva

Universidade de Sorocaba, e-mail: camila_ligero@hotmail.com,

ORCID: https://orcid.org/0000-0002-4514-3246

Stefanni Laturraghe de Moraes Melo

Universidade de Sorocaba, e-mail: stefanni.laturraghe@hotmail.com,

ORCID: https://orcid.org/0000-0002-0388-5989

Andressa Melina Becker da Silva

Universidade de Sorocaba, e-mail: andressa becker@hotmail.com,

ORCID: https://orcid.org/0000-0001-5630-7843

\section{Resumo}

O presente artigo tem como objetivo compreender o sentimento de transformação pessoal que pode ocorrer ao tornar-se mãe, buscando compreender o período puerperal e os sentimentos envoltos dessa fase. Trata-se de uma pesquisa com caráter misto e exploratória, realizada através de um questionário online, por meio do Google Forms, o qual alcançou 479 participantes. Os resultados qualitativos foram interpretados através do software IRaMuTeQ (Classificação Hierárquica Descendente, Análise de Similitude e Nuvem de Palavras) e os quantitativos pelo 
software SPSS 23.0. Através dos resultados obtidos percebeu-se que as mulheres, ao tornarem-se mães, passam por um período de ambivalência, o qual sentem um misto de emoções, tais como tristeza e felicidade. Esse momento traz impactos positivos e negativos para as mulheres, além das transformações físicas e psíquicas. Observou-se que algumas mulheres compreendem e tratam com naturalidade e tranquilidade essa nova fase, enquanto outras sentem dificuldades, colocando-se em segundo plano e acreditando que seu papel social é apenas ser mãe. Destaca-se a importância do suporte psicológico para essas mulheres, visando resgatar suas qualidades, valores e papéis sociais, além do ser mãe.

Palavras-chave: Período pós-parto; Psicologia; Relações mãe-filho; Identidade de gênero.

\section{Abstract}

This article aims to understand the feeling of personal transformation that can occur when becoming a mother, seeking to understand the puerperal period and the feelings involved in this phase. This is a mixed research and exploratory, conducted through an online questionnaire, through Google Forms, which reached 479 participants. Qualitative results were interpreted using IRaMuTeQ software (Descending Hierarchical Classification, Similitude Analysis and Word Cloud) and quantitative results using SPSS 23.0 software. Through the results obtained it was noticed that women, when becoming mothers, go through a period of ambivalence, which feel a mixture of emotions, such as sadness and happiness. This moment brings positive and negative impacts to women, beyond the physical and psychic transformations. It has been observed that some women understand and treat this new phase naturally and calmly, while others experience difficulties, putting themselves in the background and believing that their social role is only to be a mother. The importance of psychological support for these women is highlighted, aiming to rescue their qualities, values and social roles, besides being a mother.

Keywords: Postpartum period; Psychology; Mother-child relations; Gender identity.

\section{Resumen}

Este artículo tiene como objetivo comprender lo sentimiento de transformación personal que puede ocurrir al convertirse en madre, buscando comprender el período puerperal y los sentimientos involucrados en esta fase. Esta es una investigación mixta y exploratoria, realizada a través de un cuestionario en línea, a través de Formularios de Google, que llegó a 479 participantes. Los resultados cualitativos se interpretaron con el software IRaMuTeQ (Clasificación jerarquizada descendente, Análisis de Similitud y Nube de palabras) y los resultados cuantitativos con el software SPSS 23.0. A través de los resultados obtenidos as notó que las mujeres, al convertirse en madres, atraviesan un período de ambivalencia, que siente una mezcla de emociones, como la tristeza y la felicidad. Este momento trae impactos positivos y negativos a las mujeres, más allá de las transformaciones físicas y psíquicas. Se ha observado que algunas mujeres entienden y tratan esta nueva fase de forma natural y tranquila, mientras que otras experimentan dificultades, se sitúan en un segundo plano y creen que su papel social es solo ser madre. Destaca la importancia del apoyo psicológico para estas mujeres, con el objetivo de rescatar sus cualidades, valores y roles sociales, además de ser madre.

Palabras clave: Período posparto; Psicologia; relaciones madre-hijo; identidad de género. 


\section{Introdução}

Gravidez, parto e puerpério continuam sendo alvo de muitos estudos na tentativa de elucidar pontos ainda não desvendados. A gravidez é um estado resultante da fecundação de um óvulo pelo espermatozoide que envolve o subsequente desenvolvimento do feto gerado, no útero, até a sua expulsão, ou seja, parto propriamente dito (Leite, Rodrigues, Souza, Melo, \& Fialho, 2014). Além dessa concepção fisiológica há também transformações psíquicas e sociais. O período de gestação perdura aproximadamente 38 semanas e durante esse período ocorrem constantes transformações na mulher, para que esteja preparada ao desafio de tornar-se mãe. Visto que a maternidade é um momento único na vida e diante disso, se faz necessário os cuidados físicos e psíquicos dessa mulher para que ela se sinta fortalecida para cuidar de seu bebê (Zanatta, Pereira, \& Alves,2018).

O puerpério se caracteriza pela expulsão da placenta que abrigou o feto durante a gestação e do retorno ao tamanho uterino que gestou o bebê às suas condições normais (Mestieri \& Meneguette, 2005). Este período se caracteriza desde o nascimento do bebê, até 45 a 60 dias após o nascimento da criança. Devido a um decréscimo dos níveis hormonais, considera-se esta uma etapa de grande sensibilidade, vulnerabilidade, ansiedade, preocupações e com isso a mulher passa a assumir uma nova identidade, a de mãe. A gravidez poderá vir a ser um evento de situações tanto positivas quanto negativas (Maldonado, 2017).

O período puerperal não deve ser visto como um evento isolado na vida da mulher. Ela deve ser compreendida em sua totalidade como uma pessoa sob o impacto de grande mudança em sua existência, pelo fato de se assumir um novo papel social, visto que passa a viver sob condição de seu filho, exercendo a função de cuidar dele (Badinter, 2011). Essa nova configuração familiar irá levar um tempo para se reorganizar, pois além de seus antigos papéis é necessário configurar um espaço psíquico para a nova função "ser mãe" (Estrela, Machado \& Castro, 2016).

Para a mulher que se torna mãe, este período implica em mudanças anatômicas, psicológicas, fisiológicas e sociais. Além da desorganização emocional, as dificuldades de romper vínculos e a perda de identidade feminina, pois nesse período a mulher se sente culpada em pensar em si (Merighi, Gonçalves, \& Rodrigues, 2006).

Desde os primórdios, no Brasil, o nascimento é considerado um acontecimento natural, de alegria, comemorações, permeado de diversos significados culturais. Tal 
evento é vivenciado como um dos fatos marcantes da vida (Brasil, 2003). A mulher era vista como procriadora, uma pessoa que gerava espécie igual a seus pares e submissa ao papel ideal imposto socialmente. Atualmente, após reivindicações feministas referente ao modelo patriarcal, houve mudanças significativas no status da mulher, apesar de limitada a alguns grupos sociais, mudanças como independência financeira, autonomia e liberdade de expressão (Coutinho \& Menandro, 2015).

Nas reivindicações feministas, desde a primeira onda feminista junto a história afro-americana por vota de 1920, apesar de haver discussões a respeito do tema desde 1650 (Beebe, Davis, \& Gleadle; Taylor, 1998), as mulheres lutam para conquistar uma parcela do seu espaço na sociedade, tais como direito de escolha, liberdade de expressão e independência financeira (Cuevas \& Rennison, 2016). Com isso, pode-se dizer que culturalmente as mulheres, brancas e de classe média, passaram a ter menos filhos na medida em que foram assumindo outros papéis, inclusive a ter o controle sobre seu próprio corpo, levantando a possibilidade de escolha entre ter ou não filhos. Entretanto, sabe-se que muitos direitos ainda são restritos não apenas devido a misoginia, mas também ao preconceito racial, ou seja, o sistema patriarcal ainda não foi superado e necessita ser discutido.

Apesar de um número crescente de mulheres conseguirem refletir sobre a decisão, muitas sentem que seu papel de mulher é deixado de lado em substituição ao de ser mãe, o que pode interferir na sua identidade social (Greinert \& Milani, 2015; Zerach \& Magal, 2016). Identidade social é um conceito dialético envolvendo indivíduo e sociedade, ligado a pertença aos grupos sociais e seu significado emocional (Tajfel, 1978). Ao se perceber como membro de um determinado grupo social auxilia-se na formação da identidade social em uma aproximação de grupos semelhantes e afastamento de grupos alheios (Tajfel, 1978). Em alguns casos a identidade social do ser mãe acaba afastando a identidade social do ser mulher, esta estabelecida socialmente em uma sociedade patriarcal, o que pode ser prejudicial tanto para a mulher quanto para a bebê.

A partir da maternidade e desse natural afastamento, surgem as desorganizações emocionais, tais como medos e sentimento de impotência que podem contribuir e desencadear a depressão pós-parto, pois a mulher em meio à confusão de sentimentos tem que desempenhar todos os seus papéis. A falta de cuidado, preocupação, atenção com a puérpera pode dificultar a assimilação da identidade feminina (Greinert \& Milani, 2015). E entre todas as transições que o sistema familiar enfrenta, a transição para a 
parentalidade é destacada como uma das mais dramáticas e intensas (Ngai \& Ngu, 2013), requerendo reorganização de identidades e papéis (Zerach \& Magal, 2016).

A tarefa de cuidado com o bebê vem repleta de regras socialmente impostas, que ditam o que deve ou não ser feito. Aquilo que é esperado da mulher gera dúvidas sobre a capacidade de cuidar de outra vida (Gonçalves, 2008). As reações emocionais na puérpera indicam de algum modo, que necessidades básicas não estão sendo satisfeitas, demandando uma melhor compreensão que deve ser considerada tão importante quanto os cuidados físicos. Esse período é responsável por acentuar a sensibilidade da mulher, podendo levá-la a um estado de confusão e até mesmo de desespero (Maldonado, 2017).

Dentre as mudanças que a mulher ao se tornar mãe transcorre, estão as mudanças físicas, que por vezes são drásticas, passando a não se reconhecer (Aching, Biff, \& Granato, 2016). Primo, Dutra, Lima, Alvarenga e Leite (2015) destacam a importância do aleitamento materno que, apesar de ser socialmente imposto como algo fácil, pode causar na mulher o não reconhecimento de si, pois seu papel feminino passa a ser reconhecido como reprodutora.

É socialmente imposto que a mãe é capaz de cuidar do seu filho sozinha, sem precisar de uma rede de apoio que a auxilie nos aspectos físicos ou psicológicos durante esse momento de sua vida. Portanto, a família representa o agente socializador primário que pratica o cuidado, que dá apoio e orientações, que ensina a viver, amar, sentir, a se cuidar e cuidar do outro (Teixeira, 2011).

\section{Objetivos}

Entendendo que existem dificuldades ao assumir esse novo papel social, o de ser mãe e a falta de suporte familiar (rede de apoio), este trabalho se justifica socialmente, bem como em caráter científico, ao se perceber que muitas mulheres ainda precisam refletir sobre sua vida, seus papeis sociais, inclusive questionando-os. Tendo em vista que ele será embasado teoricamente em aspectos sociais e de saúde relacionados a Psicologia. Assim, o presente estudo objetiva compreender o sentimento de transformação pessoal que pode ocorrer ao tornar-se mãe.

\section{Método}

A presente pesquisa tem o caráter misto, ou seja, qualitativo e quantitativo, exploratório. A pesquisa qualitativa exploratória busca a partir da compreensão de um 
grupo social levantar dados relevantes sujeitos a análises na produção de novas informações, além de uma familiarização com o tema a fim de torná-lo mais explícito (Gil, 2017). Em contrapartida, a pesquisa quantitativa, busca a partir de números estatísticos quantificar pessoas, opiniões e informações, com isso busca-se através de um raciocínio lógico mensurar experiências humanas (Gil, 2017).

\section{Participantes}

Participaram da pesquisa 479 mulheres mães, com idades entre 16 a 77 anos (M $=34,04 ; \mathrm{DP}=9,53)$. Como não houve identificação das participantes e se trata de uma pesquisa online, há a dispensa do parecer de aprovação de um Comitê de Ética em Pesquisa, de acordo com a Resolução 510 de 07 de abril de 2016 (Conselho Nacional de Saúde).

A maioria das respondentes mora no estado de São Paulo $(88,50 \%)$, o que já era esperado, tendo em vista que as pesquisadoras residem nesse estado, mas, conseguiu-se uma abrangência em outros nove estados brasileiros - Paraná, Santa Catarina, Minas Gerais, Goiás, Rio de Janeiro, Espírito Santo, Bahia, Rio Grande do Sul e Alagoas. As mulheres possuem de um a oito filhos $(\mathrm{M}=1,57$; $\mathrm{DP}=1,10)$, sendo que a maioria $(57,60 \%)$ possui um filho e $31,30 \%$ possuem dois filhos. A maioria possui filhos entre um a cinco anos $(33,90 \%)$, seguido de zero a um ano $(27,20 \%)$.

\section{Instrumentos}

Para esta pesquisa foi desenvolvido, através do Google Forms, um questionário online. Este foi composto por 14 perguntas, destinadas somente a mulheres mães. $\mathrm{O}$ questionário foi disponibilizado em cinco grupos de mães nas plataformas online, Facebook, Whatsapp e Instagram no quais ficou disponível por dez dias. As questões fechadas eram: Você aceita colaborar conosco e participar desta pesquisa? Qual sua idade? Qual cidade reside atualmente? Quantos filhos você tem? Qual a idade deles (as)? As questões abertas eram: Quais os sentimentos identificados por você no período pósparto? Após o nascimento do bebê você pensava em si? Ao se olhar no espelho após a chegada do bebê, você se reconheceu como antes? Se não, o que mudou? Conseguiu exercer as funções do trabalho e da vida social que tinha anterior ao parto? Como se percebe no pós-parto (emocionalmente e fisicamente)? Como foi sua adaptação ao ambiente com o bebê? Você conseguiu manter relações sexuais como anteriormente a 
gestação? Você se sentiu cuidada no pós-parto (quarentena)? Você sentiu que seu filho(a) teve mais atenção que você? Se sim, como foi? (Neste caso, mulheres que tinham mais de um filho, escolhiam livremente sobre qual gestação falariam, até para que relatassem a mais marcante).

\section{Procedimentos e análise de dados}

As análises das questões sociodemográficas e algumas perguntas fechadas foram avaliadas via métodos quantitativos. Para isso utilizou-se o software Statistical Package for the Social Science - Pacote Estatístico para Ciências Sociais (SPSS 23.0). Utilizouse os seguintes métodos estatísticos: Análises descritivas como média, desvio-padrão e frequência; assim como análises inferências como a Correlação de Spearman e teste de Kruskall-Wallis, tendo em vista que os dados não apresentaram distribuição normal e homogênea (verificado pelos testes Kolmogorov-Smirnov e Levene), considerando um nível de significância de $\mathrm{p} \leq 0,05$.

Para a realização das análises qualitativas da pesquisa utilizou-se o software IRaMuTeQ no qual as organizou-se as respostas obtidas em um corpus de análise (Camargo \& Justo, 2015), sendo cada pergunta uma linha de comando. Posteriormente, foram utilizados a Classificação Hierárquica Descente (CHD), a Análise de Similitude e a Nuvem de Palavras, por meio do software. Segundo Chartier e Meunier (2011), o IRaMuTeQ tem o rigor estatístico que permite utilizar vários recursos técnicos de análise lexical, é simples e de fácil entendimento. Isso posto o software pode auxiliar e contribuir para os estudos voltados para área de Ciências Humanas e Sociais, que utiliza de conteúdo simbólicos. O software se faz necessário para analisar uma preciosa fonte de dados, uma vez que é importante para pesquisa acadêmica e com isso auxiliar a comunidades com seus resultados. Este programa informático realiza diversos tipos de análise de dados, desde as mais simples (lexicografia, frequência de palavras), até as mais elaboradas, como a Classificação Hierárquica Descendente e Análise de Similitude. A partir dos resultados gerados, analisou-se os conteúdos e as classificações propostas para sua posterior discussão.

\section{Resultados}

As perguntas fechadas foram analisadas de maneira descritiva quantitativamente, em relação a percepção das mulheres no puerpério, os cuidados em relação a si e a perda da identidade feminina. Os resultados são apresentados na Tabela 1. 
Tabela 1.

Resultados descritivos sobre o puerpério e a identidade feminina

\begin{tabular}{|c|c|c|c|}
\hline Perguntas/Respostas & $\begin{array}{c}\text { Sim } \\
f(\%)\end{array}$ & $\begin{array}{l}\text { Não } \\
f(\%)\end{array}$ & $\begin{array}{l}\text { Indecisão } \\
\quad f(\%)\end{array}$ \\
\hline Após o nascimento do bebê você pensava em si? & $\begin{array}{c}74 \\
(15,40 \%)\end{array}$ & $\begin{array}{c}356 \\
(74,30 \%)\end{array}$ & $49(10,20 \%)$ \\
\hline $\begin{array}{l}\text { Ao se olhar no espelho após a chegada do bebê, você se } \\
\text { reconheceu como antes? }\end{array}$ & $\begin{array}{c}93 \\
(19,40 \%)\end{array}$ & $\begin{array}{c}386 \\
(80,60 \%)\end{array}$ & $\begin{array}{c}0 \\
(0,00 \%)\end{array}$ \\
\hline $\begin{array}{l}\text { Conseguiu exercer as funções do trabalho e da vida social } \\
\text { que tinha anterior ao parto? }\end{array}$ & $\begin{array}{c}139 \\
(29,00 \%)\end{array}$ & $\begin{array}{c}268 \\
(55,90 \%)\end{array}$ & $71(14,80 \%)$ \\
\hline $\begin{array}{l}\text { Você conseguiu manter relações sexuais como } \\
\text { anteriormente a gestação? }\end{array}$ & $\begin{array}{c}109 \\
(22,80 \%)\end{array}$ & $\begin{array}{c}343 \\
(71,60 \%)\end{array}$ & $\begin{array}{c}27 \\
(5,60 \%)\end{array}$ \\
\hline Você se sentiu cuidada no pós-parto (quarentena)? & $\begin{array}{c}300 \\
(62,60 \%) \\
\end{array}$ & $\begin{array}{c}129 \\
(26,90 \%)\end{array}$ & $50(10,40 \%)$ \\
\hline Você sentiu que seu filho(a) teve mais atenção que você? & $\begin{array}{c}263 \\
(55,40 \%)\end{array}$ & $\begin{array}{c}193 \\
(40,60 \%)\end{array}$ & $\begin{array}{c}19 \\
(4,00 \%)\end{array}$ \\
\hline
\end{tabular}

Pela Tabela 1 é possível perceber que a maioria das mulheres não pensava em si após o nascimento do bebê, não se reconhecia ao olhar no espelho, não conseguiu exercer funções do trabalho, da vida social e manter relações sexuais como anteriormente a gestação, se sentiu cuidada durante a quarentena, mas sentiu que o filho teve mais atenção que ela própria. Em relação a Correlação de Spearman, observou-se uma correlação significativa entre algumas variáveis. As correlações estatisticamente significativas foram expressas na Tabela 2.

Tabela 2.

Resultados significativos da Correlação de Spearman (rho)

\begin{tabular}{|c|c|c|c|c|c|c|}
\hline & $\begin{array}{l}\text { Quantos } \\
\text { filhos? }\end{array}$ & $\begin{array}{l}\text { Idade } \\
\text { filhos? }\end{array}$ & $\begin{array}{l}\text { Ao se olhar no } \\
\text { espelho após a } \\
\text { chegada do } \\
\text { bebê, você se } \\
\text { reconheceu } \\
\text { como antes? }\end{array}$ & $\begin{array}{l}\text { Conseguiu exercer } \\
\text { as funções do } \\
\text { trabalho e da vida } \\
\text { social que tinha } \\
\text { anterior ao parto? }\end{array}$ & $\begin{array}{l}\text { Você conseguiu } \\
\text { manter relações } \\
\text { sexuais como } \\
\text { anteriormente a } \\
\text { gestação? }\end{array}$ & $\begin{array}{c}\text { Você se } \\
\text { sentiu } \\
\text { cuidada no } \\
\text { pós-parto } \\
\text { (quarentena)? }\end{array}$ \\
\hline Idade & $0,266^{* *}$ & $0,533 * *$ & - & $-0,111^{*}$ & - & - \\
\hline Estado & $0,093^{*}$ & - & $-0,129$ & - & - & - \\
\hline Quantos filhos & - & $0,556^{* *}$ & - & $-0,117^{*}$ & - & - \\
\hline Idade filhos & - & - & - & $-0,168^{* *}$ & $-0,153 * *$ & - \\
\hline $\begin{array}{l}\text { Após o nascimento do bebê } \\
\text { você pensava em si? }\end{array}$ & - & - & $0,163 * *$ & - & - & - \\
\hline $\begin{array}{l}\text { Ao se olhar no espelho após a } \\
\text { chegada do bebê, você se } \\
\text { reconheceu como antes? }\end{array}$ & - & - & - & $0,168 * *$ & $0,105^{*}$ & $0,127 * *$ \\
\hline $\begin{array}{l}\text { Conseguiu exercer as funções } \\
\text { do trabalho e da vida social que } \\
\text { tinha anterior ao parto? }\end{array}$ & - & - & - & - & $0,209 * *$ & $0,164 * *$ \\
\hline $\begin{array}{l}\text { Você conseguiu manter } \\
\text { relações sexuais como } \\
\text { anteriormente a gestação? }\end{array}$ & - & - & - & - & - & $0,106^{*}$ \\
\hline
\end{tabular}

Nota: $* \mathrm{p} \leq 0,05 ; * * \mathrm{p} \leq 0,001 ;$ - não significativo. 
Pela Tabela 2 é possível observar que quanto mais velha a mulher, maior é a quantidade de filhos, mais velhos eles são e mais essa mulher conseguiu exercer as funções do trabalho e da vida social que tinha anterior ao parto.

Mulheres que moram em São Paulo, Paraná e Santa Catarina possuem menos filhos que as que moram na Bahia e Alagoas, por exemplo; assim como não conseguiam se reconhecer no espelho após a chegada do bebê, comparando a antes do parto. Mulheres com mais filhos, tinham os filhos mais velhos e conseguiam exercer as funções do trabalho e da vida social que tinha anterior ao parto. Quanto mais velhos os filhos, mais as mulheres conseguiam exercer as funções do trabalho e da vida social, assim como manter relações sexuais (Tabela 2).

Mulheres que não pensavam em si após o nascimento do bebê também tinham dificuldade de se reconhecer ao se olhar no espelho. As que não conseguiam se reconhecer ao se olhar no espelho, não conseguiam exercer as funções do trabalho e da vida social, nem ter relações sexuais, como as anteriormente ao parto; também não se sentiram cuidadas no pós-parto. Mulheres que não conseguiram exercer as funções do trabalho e da vida social como tinham antes do parto também não conseguiram manter relações sexuais como antes, nem se sentiram cuidadas no pós-parto. Por fim, quem não conseguiu manter relações sexuais, também não se sentiu cuidada no pós-parto (Tabela 2).

Pelo teste de Kruskall-Wallis, houve uma relação significativa entre pensar em si após ter tido filho e se reconhecer como antes após a chegada do bebê $(p<0,001)$ e conseguir ter relações sexuais como antes do parto $(p<0,05)$. Ambas como uma relação positiva (diretamente proporcional).

$\mathrm{Na}$ sequência são apresentados os resultados das análises qualitativas. As perguntas que foram analisadas pelo software IRaMuTeQ continham os relatos descritos de mães. A partir da Classificação Hierárquica Descendente (CHD), foram analisados o corpus de 506 segmentos de texto (ST), retendo-se 79,64\% do total, os quais geraram cinco classes. Pela CHD é possível observar que o corpus "A perda da identidade feminina ao tornar-se mãe" inicialmente se dividiu em dois subcorpus: o primeiro composto pelas classes 4, 2, 3 e 5 e o segundo composto pela classe 1 . O software ainda dividiu esse subcorpus novamente, opondo a classe 5 às classes 2, 3 e 4 . Houve mais uma 
divisão em que a classe 4 se opôs às classes 2 e 3 . Por fim, houve a última divisão, em que se opôs às classes 2 e 3 . Estes resultados são apresentados na Figura 1.

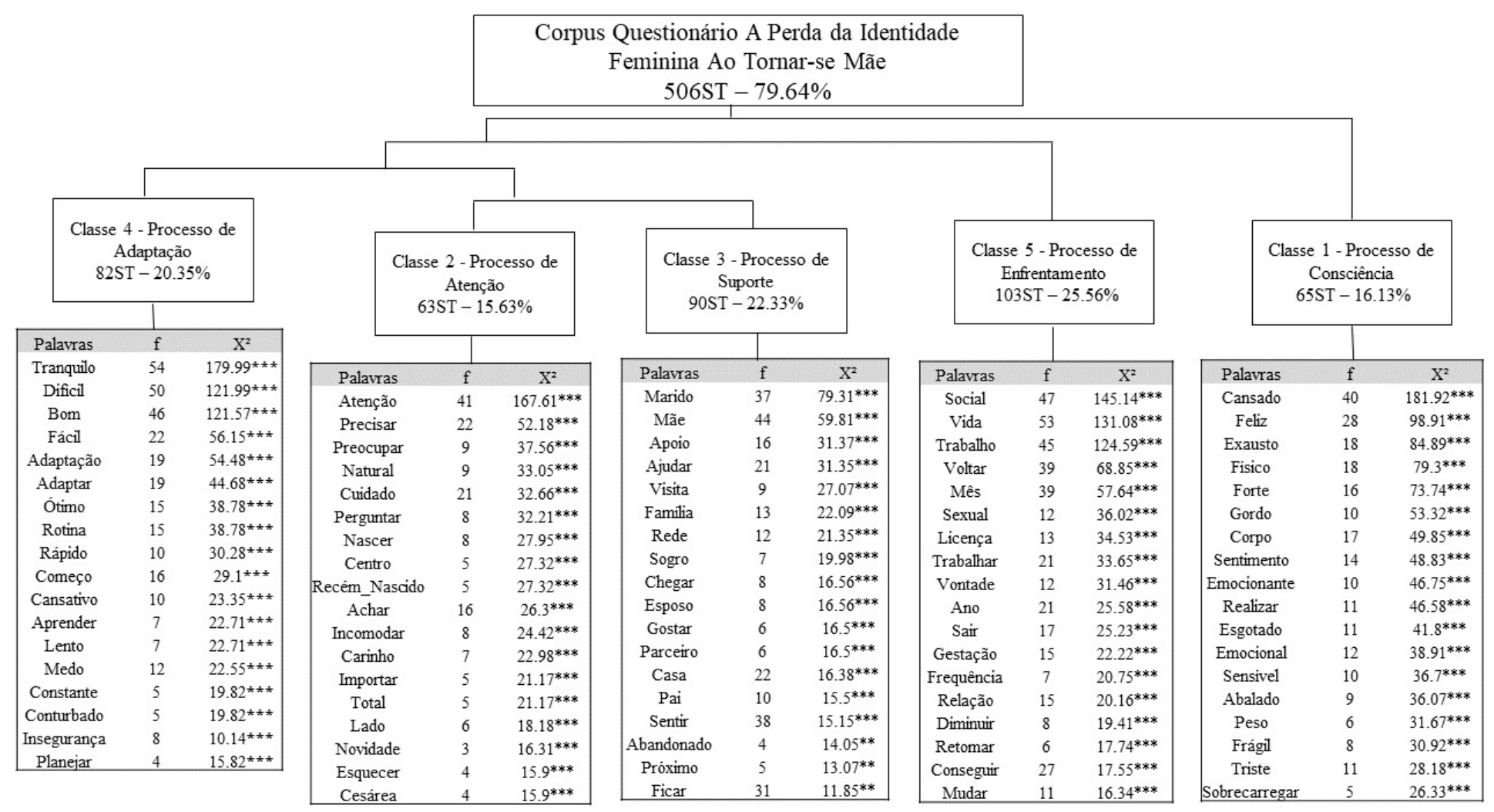

Figura 1.

Resultados da análise pela Classificação Hierárquica Descendente (CHD) pelo software IRaMuTeQ - Dendograma.

Nota: $* \mathrm{p} \leq 0,05 ;{ }^{* *} \mathrm{p} \leq 0,01 ; * * * \mathrm{p} \leq 0,001$

Classe 1 "processo de consciência " analisou-se respostas das mulheres/mães quando exercem a função de ser mãe e como percebem seu estado físico e emocional após o nascimento do bebê. Nessa amostra ficaram evidentes algumas palavras, sendo elas: cansado, feliz, exausto, forte, corpo, gordo, esgotado, triste e frágil. Notou-se o quão dificultoso é a adaptação da rotina com o bebê e o quanto essa fase as deixam fragilizadas. Observou-se que muitas mulheres se sentiram felizes pela chegada do bebê, por ter realizado o desejo de ser mãe e ser responsável por uma nova vida. Destaca-se também o conflito em lidar com a mudança física e emocional. Com isso é possível perceber nos discursos escritos das participantes o quanto a mulher/mãe necessita de cuidados físicos e psicológicos. Para elucidar essa nossa discussão apresentaremos algumas respostas das participantes: 
No inicio eu tinha vergonha por ter engordado e hoje já me acostumei, mas a frequência não é a mesma, é difícil porque as três crianças acabam nos deixando bem cansados. (Ind.474; 28 anos; um filho de nove anos).

Feliz por ter a bebê, triste pela transformação no corpo, cansada fisicamente e querendo um tempinho para mim. (Ind.264; 23 anos; um filho de um ano e um mês).

No início foi muito dificil, mas agora estou bem melhor. Às vezes cansada, mas extremamente feliz e realizada. (Ind. 291; 35 anos; um filho de 4 meses).

Na Classe 2 intitulada de "Processo de atenção" analisaram-se as formas como as mulheres vivenciaram o pós nascimento de seu(s) filho(s) possibilitando compreender que muitas delas não se sentiram cuidadas, mesmo que em partes, pelo grupo de apoio, o qual poderia ser seu parceiro ou familiares. As palavras de mais relevância nessa classe foram: atenção, precisar, natural, incomodar, carinho e preocupar. Perante a análise da amostra foi possível identificar o quanto as mulheres mães sentiram falta de cuidados, carinho e atenção, bem como o desconforto de incomodar por estar precisando de auxílio. Com isso é perceptível que a mãe se sinta esquecida, pois ela passou por um momento crítico e precisa de cuidados físicos, emocionais e psicológicos. Observou-se também que para uma parte da amostra a atenção voltada para o bebê era considerada natural, deixando-as felizes, pois percebiam que seu filho(a) era amado(a) por todos a sua volta e isso para as respondentes era uma forma de cuidado. Como apresentado em algumas respostas das participantes:

Sim e não; sim porque fui cuidada e não porque que acho que a atenção volta muito pro bebê e você acaba sendo deixada de lado. (Ind. 18; 34 anos; dois filhos - três anos e meio e outro de sete anos).

Bebês sempre são o centro das atenções é natural o interesse no bebê, eu me sentia muito feliz em vê-la receber tantos carinhos. (Ind.163; 31 anos; um filho de três meses).

A Classe 3 denominada de "Processo de suporte" fala sobre o quanto a mulher/mãe tinha a sua rede de apoio. $\mathrm{Na}$ amostra foram analisadas as relações com a família, marido e a mãe, bem como a rede de apoio. A análise indicou que a maioria das mulheres teve respaldo da mãe e do marido. Uma outra parte da amostra se sentiu abandonada pelos familiares e parceiros, alegando a falta de ter alguém por perto, como a mãe por exemplo, para poder auxiliar em momentos de cuidados com o bebê. As palavras que se destacaram nessa classe foram: mãe, marido, família, ajuda, apoio, sentir e abandonado como demonstra algumas respostas a seguir:

Não, nessa parte tive sorte de ter minha mãe ao meu lado que me deu muita atenção. (Ind. 46; 30 anos; dois filhos - 13 e 6 anos). 
Sim, en e meu marido não tivemos rede de apoio, focamos tudo no nosso bebê, eu não conseguia fazer nada para mim e meu marido não percebeu que eu também precisava de atenção. (Ind.312; 37 anos; três filhos - oito, seis e quatro anos).

Sim, não tive rede de apoio, todos os cuidados com ele eram feitos por mim me deixando de lado em todos os sentidos por pura exaustão. (Ind. 327; 41 anos; um filho de 6 meses).

A Classe 4 intitulada "Processo de adaptação" retrata que na amostra analisou-se o quanto as mulheres/mães dividiram opiniões em relação a adaptação com a nova fase. Uma parte das mulheres relatou que foi um processo tranquilo e fácil, enquanto para as outras foi um processo difícil, pois tiveram que se adaptar a uma nova rotina com o bebê, o que se tornou cansativo, conturbado e exaustivo.

Cansativo, exaustivo, tanto fisicamente como mentalmente e emocionalmente. (Ind. 106; 56 anos; três filhos - 29, 28 e 21 anos).

Foi tranquilo, apesar das inseguranças me sinto orgulhosa de mim por ter conseguido e ainda estar conseguindo, aprendendo um dia de cada vez. (Ind. 119; 37 anos; um filho de um ano e um mês).

Por fim, a partir da Classe 5 denominada de "Processo de enfrentamento" analisaram-se as relações sociais, atividade sexual e o retorno ao trabalho das mulheres. As palavras que foram mais significantes nessa análise foram: social, vida, frequência, sexual, trabalho, voltar e relação. A vida social da mulher aparentemente no pós-parto fica prejudicada pois, ela não se reconhece pertencente ao grupo que fazia parte, se sentindo muitas vezes deslocada do seu meio. Preferem muitas vezes sair com pessoas que também tenham filhos ou pessoas mais velhas. Houve relatos em que amigos(as) deixaram de convidá-las para eventos por terem filhos.

Uma pequena parte da amostra não conseguiu retornar ao trabalho tranquilamente e outras pediram demissão. A análise também mostrou a dificuldade das mulheres em manter a sexualidade ativa. Muitas mulheres/mães relataram sentir dores, além da diminuição significativa da libido, o que favorece uma redução de desejos sexuais com seus parceiros. Outra parte da amostra relatou exercer suas funções sexuais com a mesma frequência que antes, durante e depois da gravidez. Diante disso é importante o cuidado psicológico e emocional.

Vida social sim, claro que adaptadas a ambientes que encaixasse o bebê, o trabalho sai para ter mais tempo para ele. (Ind. 83; 33 anos; dois filhos - oito e três anos).

Não, vivo apenas para ser mãe, não tenho contato com amigas, só por WhatsApp e socializar é algo que não existe pra mim, tento trabalhar em casa, mas é bem difícil e mais exaustivo. (Ind.318; 43 anos; um filho de nove anos). 
Minha relação sexual melhorou durante a gestação e após o parto quando comparada à antes da gestação. (Ind. 454; 25 anos; um filho de um ano).

O outro método utilizado foi a Análise de Similitude. Os resultados são demonstrados na Figura 2.

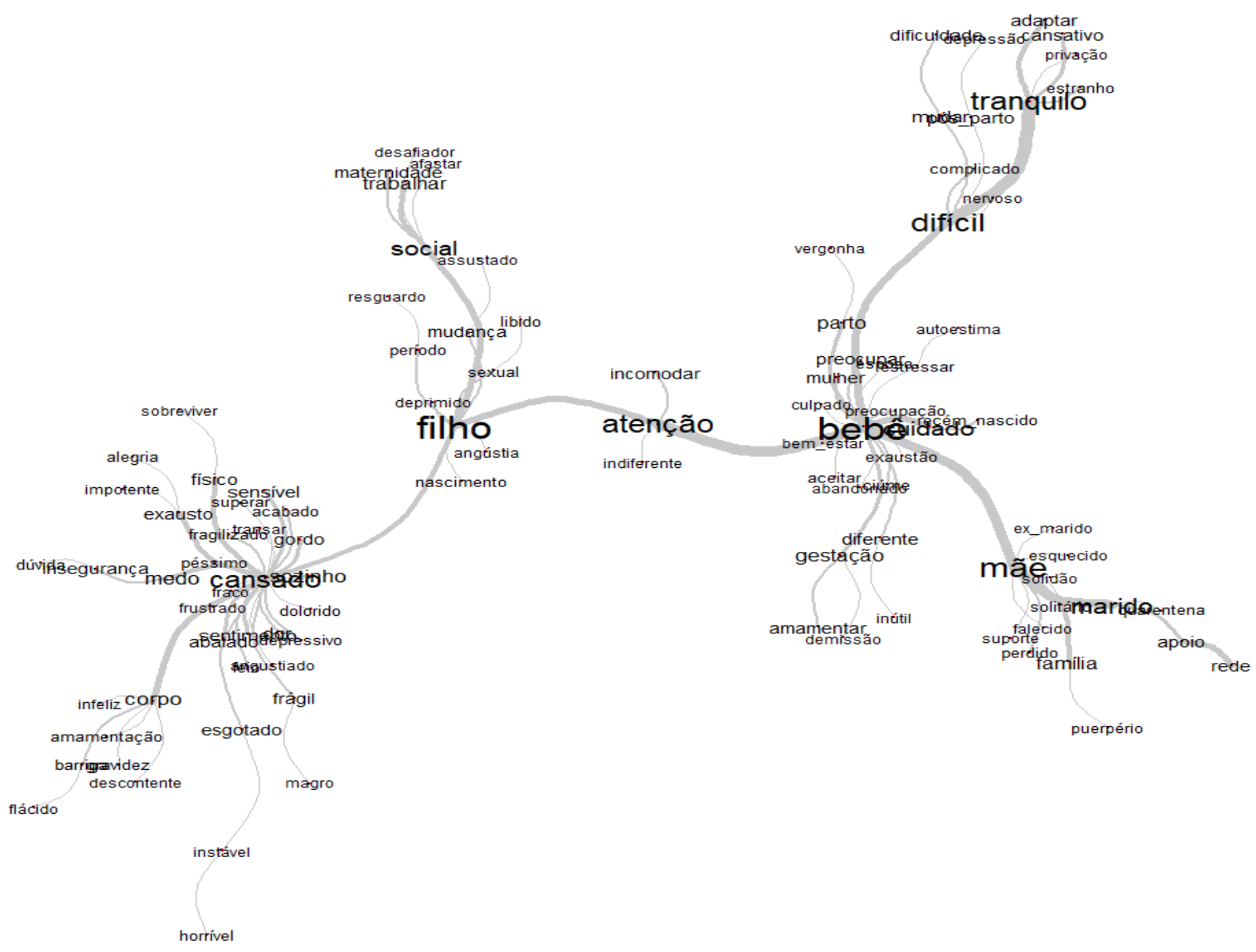

\section{Figura 2.}

Resultado da Análise de Similitude pelo software IRaMuTeQ.

A Análise de Similitude possibilita a identificação das repetições das palavras que resultam em uma estrutura na qual elas se assemelham e se distinguem formando conexões através de suas especificidades, sendo utilizada nesse estudo para a visualização das co-ocorrências de palavras (Camargo \& Justo, 2015). A partir da análise de similitude pode-se identificar que a estrutura gráfica se dividiu em cinco grandes eixos, sendo eles: cansado, filho, atenção, bebê e mãe. Pode-se destacar que o eixo atenção estabelece relação com os demais sentimentos percebidos pela mulher. Como elucidado nos discursos a seguir: 
No primeiro que foi parto normal foi como se não tivesse passado por nada, andei normal fiz quase tudo. No segundo e terceiro que foi cesárea já foi mais complicado, nos 3 primeiros dias emocionalmente foi tranquilo porque nasci para ser mãe, cada um foi único para mim. (Ind. 49; 35 anos; um filho de um ano).

Com certeza para a sociedade nasce um bebê e morre uma mulher. O reconhecimento e cuidado da mãe só acontecem com muita luta. (Ind. 153; 34 anos; dois filhos - dois anos e sete meses, e cinco meses).

Cansada, angustiada, sensação de culpa frequente. (Ind. 404; 39 anos; dois filhos de oito meses).

A última análise realizada foi a nuvem de palavras, a qual esboça a representatividade dos termos em relação ao corpus como um todo. $\mathrm{O}$ objetivo de sua utilização nesse trabalho foi a visualização, em uma forma estética, da frequência das palavras, o que é representativo para o presente contexto. Os resultados são apresentados na Figura 3.

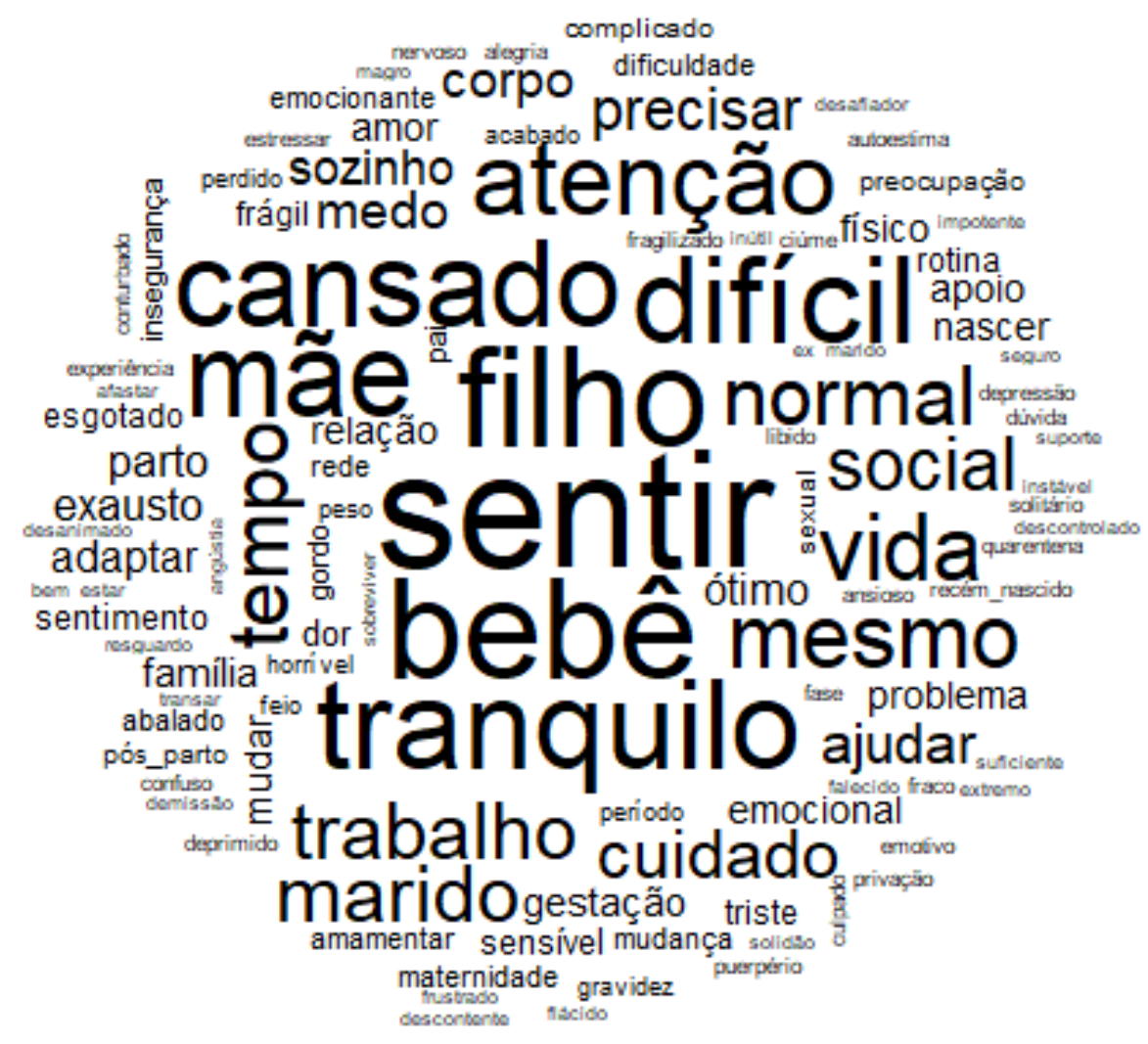

Figura 3.

Resultados da nuvem de palavras gerada pelo corpus "A perda da identidade feminina ao tornar-se mãe". 
Pela Figura 3 é possível observar que as palavras são posicionadas aleatoriamente de tal forma que as mais frequentes aparecem maiores que as outras, demonstrando, assim, seu destaque no corpus de análise da pesquisa, sendo elas: sentir, filho, bebê, tranquilo, cansado, difícil, mãe, atenção, social, normal, vida, tempo, trabalho, marido e cuidado. Estas se relacionam no sentido de como a mulher se percebe no período puerperal. Como exemplificados nos discursos a seguir:

\begin{abstract}
Não me reconheci e até hoje não me reconheço, mudou muita coisa, eu tinha novos pensamentos que nunca imaginei ter, como cuidado extremo e sensações de arrependimento, pois agora tinha uma vida em minhas mãos e ao mesmo tempo sentia um amor gigantesco e me sentia mal por me sentir arrependida de ter uma filha. Depois passei a me sentir muito feliz e grata por ter uma filha, porém foi doloroso me adaptar a ter uma rotina e nesta rotina $99 \%$ do tempo é voltado para minha filha. (Ind.377; 23 anos; dois filhos de seis meses).
\end{abstract}

Foi tranquilo, fiquei sozinha e logo me virei, sempre fui prática e não me deixei abalar. (Ind. 118; 31 anos; um filho de seis anos).

Sim, para mim foi algo normal, pois meu filho precisava de mais atenção do que eu. (Ind. 33; 25 anos; um filho de três meses).

\title{
Discussão
}

Com base nos resultados obtidos percebe-se que as mulheres/mães após o nascimento do bebê aparentemente não conseguem pensar em si. Segundo Winnicott (2000), esta relação simbiótica se dá porque um bebê não existe sozinho, visto que é constituído a partir de uma relação entre biológico e psíquico no qual a mãe suficientemente boa deve estar disposta a estabelecer um ambiente bom para o crescimento psíquico de seu bebê. Esta preocupação em se tornar uma boa mãe, pode trazer para a mulher o sofrimento e angústia de não se reconhecer e não conseguir exercer suas funções sociais e sexuais (Giordani, Piccoli, Bezerra \& Almeida, 2018). Baseandose nesses aspectos, fica perceptível que as mulheres passam por mudanças significativas, com isso se inicia uma desorganização de sentimentos, os quais geram na mulher uma confusão de papéis (Greinert \& Milani, 2015).

Observa-se na amostra os sentimentos ambivalentes que acometem as mulheres neste período, no qual relataram que esse momento é conturbado, tranquilo, natural, difícil, além de se sentirem felizes e cansadas, o que compromete à identificação com os papéis que exerciam anterior à gestação e ao nascimento de seu filho. Se caracterizando assim, como um ganho para que estas mulheres estejam regredidas para exercer a função de maternar seu bebê e perceber suas necessidades (Andrade, Baccelli \& Benincasa 2017). Ainda para Andrade, Baccelli e Benincasa (2017) o período pós-parto é marcado 
por sentimentos ambivalentes que transitam entre euforia, angústia, desconforto físico que é inerente ao parto, medo das funções maternas como amamentar e medo de não conseguir suprir as necessidades do bebê ou de ser boa mãe e boa mulher. Ou seja, tratase de um período ambivalente, pois apesar de algumas dificuldades encontradas, é também um momento único, ou seja, trata-se de um período no qual a mulher perde alguns papéis, mas ganha um novo: ser mãe.

Desta forma a mulher passa a questionar sua identidade feminina que está em transformação. Segundo Andrade (2016), o processo identitário do indivíduo está em constante transformação, que se dá por um conjunto de experiências, sentimentos e papéis socialmente impostos que permeiam todas as relações. Segundo Taifel (1978) o processo de identidade social se dá pela a aproximação com alguns grupos semelhantes (mães) e afastamento de outros grupos alheios (não mães), o que aparece relatado nos resultados.

Os resultados estatísticos apresentados, possibilitam mensurar que quanto mais velha a mulher, maior é a quantidade de filhos. Observa-se que desde os primórdios, no Brasil, o nascimento é considerado um acontecimento natural, assim como as mulheres eram consideradas procriadoras de sua espécie, sendo elas submissas ao papel imposto socialmente (Coutinho \& Menandro, 2015).

Historicamente percebe-se pressupostos ideológicos que permeiam à ideia que o ideal de mulher era ter filhos, o que para Badinter (2011) é uma ideia ultrapassada, visto que as mulheres podem se sentir satisfeitas em não gerar um filho, percebendo que o amor materno não é uma característica inata as mulheres, mas construída à partir da vivência e convivência, ou seja, do vínculo que esta mulher consegue estabelecer com o bebê. De acordo com Bion (1994), o vínculo é constituído à partir de um aspecto relacional, ou seja, é resultado das recíprocas influências das relações que permeiam o ambiente no qual o indivíduo está inserido baseado em relações de amor, ódio, reconhecimento ou da falta dele, além do aspecto emocional que irá resultar na forma como o indivíduo se relaciona com o meio. Esta vinculação vai para além do mundo exterior, afinal engloba o interior do indivíduo, ou seja, esta vinculação não se dá após o nascimento do bebê, mas durante à gestação na qual à mulher permanece ensimesmada para que consiga estar ligada ao bebê e à dinâmica estabelecida entre o casal que concedeu à vida do bebê.

Com base nos dados interpretados através do software IRaMuTeQ, compreendese que a falta de cuidados, suporte e atenção permeiam as mulheres no período puerperal. Neste sentido, percebe-se o quanto se torna difícil para mulher tomar consciência de seus 
sentimentos, tendo em vista que, ela passa por momentos extremos, pois durante a gestação continha toda atenção voltada para si e após o nascimento do bebê ela passa a se sentir em segundo plano. Essa situação de extremos leva a fortes impactos psicológicos (Giaretta \& Fagundez, 2015).

Com base nisso, evidenciou-se que as mulheres sentiam atenção e cuidado somente por suas mães e parceiros. Segundo Zanatta, Pereira e Alves (2017), as mulheres que se disponibilizam a função de cuidadora da mulher recém-parida sentem-se identificadas em relação a experiência de tornar-se mãe e os anseios que envolvem a trama, servindo como suporte para as angústias e frustrações advindas nesta fase. Sendo assim, esta mulher direciona e orienta a mãe recém-parida aos cuidados com o bebê, visto que a mesma já vivenciou estes sentimentos e angústias. Para isso, é necessário que a mulher recém-parida permita-se ser cuidada e assim se aplique um equilíbrio entre a presença implicada (acolher, reconhecer e interpelar) e presença reservada (dar tempo e espaço, manter-se em reserva, disponível sem intromissões excessivas), a qual estas funções precisam agir em equilíbrio dinâmico para que os cuidados efetivamente proporcionem a instalação de uma capacidade de fazer sentido no indivíduo (Figueiredo, 2009).

Observa-se também que é a partir dessa falta de atenção que surgem as conexões entre as palavras filho e bebê. A partir disso novos eixos envoltos aos sentimentos da mulher ganham espaço. Segundo Zanata, Pereira e Alves (2018), esta ligação torna-se tão evidente pelo fato de o bebê exigir da mãe os cuidados necessários para a sua sobrevivência. Este movimento que se estabelece entre mãe e bebê se caracteriza à partir da sensibilidade da mulher que é a "preocupação materna primária" na qual ela prioriza seu bebê e se concentra em segundo plano, afinal esta mulher irá intervir ativamente como construtora do espaço mental da criança formando com ela uma unidade (Mozzaquatro \& Arpini, 2015).

Lopes, Alfaya, Machado e Piccinini (2005), embasados no conceito de Winnicott do período de preocupação materna primária, pesquisaram sentimentos das mães primíparas diante da situação de separação de seus bebês e os sentimentos em relação aos cuidadores alternativos. Verificaram através dos resultados sentimentos negativos no momento da separação de seus bebês, tais como preocupação, apreensão, medo, tristeza e ansiedade. Para a mulher, nesse momento, "maternidade e trabalho" são vividos imaginariamente como concorrentes opostos na realização fálica, pelo qual o 
investimento crescente em um implicaria necessariamente o desinvestir proporcional no outro" (Jerusalinsky, 2009, p.128).

Compreende-se que o processo de adaptação da nova fase torna-se para mulher intenso, exaustivo e conturbado principalmente para mães primíparas. Assim como no processo de enfrentamento, quando chega o momento de retomar a rotina anterior ao parto, tais como relação sexual, emprego, vida social, entre outros. Destaca-se que as dificuldades em manter relações sexuais, trouxeram as mulheres, que participaram da entrevista, consequências de abandono e traição por parte de seu parceiro. Para Kerber, Enderle, Nobre, Carvalho e Braga (2015), não é o tipo de parto que interfere na vida sexual da mulher após o parto, isso vai além, pois muitas mulheres sentem dores durante a penetração enquanto outras sentem dores durante o ato sexual. Sendo assim, esta dificuldade pode comprometer negativamente a sexualidade da mesma como também o relacionamento dela junto a seu parceiro. De fato, a chegada de um filho interfere, positiva ou negativamente, na vida da mulher e as atividades anteriores ao parto tendem a ficar em um segundo plano (Piccinini, Gomes, Nardi \& Lopes, 2008).

Outro aspecto importante observado na pesquisa foi o discurso em que sentem a diminuição da libido o que é um fator influenciador da consolidação do ato sexual. Sendo assim, a atividade sexual após o nascimento do bebê deve ser compreendida e entendida com muito cuidado, afinal a mulher acaba de passar por momentos de muitas transformações corporais, psicológicas e sociais (Maldonado, 2017), além de sofrer com esses processos precisa se adaptar aos novo papéis que lhe são atribuídos (Estrela, Machado \& Castro, 2016). Por fim, observa-se que são muitas as transformações que a mulher percorre no período pós-parto, sendo elas positivas e negativas, isso varia de acordo com o contexto em que cada mulher está inserida, assim como a rede de apoio que ela possui.

\section{Considerações finais}

O trabalho objetivou compreender o sentimento de transformação pessoal que pode ocorrer ao tornar-se mãe. Apesar de o estudo contar com a participação de muitas mulheres, os resultados devem ser analisados com cautela, tendo em vista que o mesmo se limita às participantes (não foram incluídas perguntas sobre a raça e renda familiar), as perguntas e métodos utilizados. Buscou-se reduzir os efeitos das limitações, utilizando 
procedimentos estatísticos adequados, bem como uma análise de conteúdo textual via o software IRaMuTeQ, o qual diminui as interferências dos pesquisadores sobre o processo.

O trabalho aqui apresentado elucida o quanto a mulher é afetada psicologicamente no período pós-parto, pois há muitas mudanças em sua vida, tais como seu corpo, desejos, funções e pensamentos. Com isso compreende-se que a individualidade é o que distingue os indivíduos, as formas como cada mulher experiencia a maternidade se difere. Nota-se a ambivalência de sentimento vivida por cada participante, a qual para uma parte da amostra foi difícil e para outra foi tranquilo e natural. Destaca-se que essa fase varia de acordo com a individualidade de cada mulher, tornando claro que as participantes precisam de um cuidado psicológico e não somente físico.

No decurso da pesquisa pode-se perceber que mães primíparas sofrem mais os impactos dos novos papéis sociais que lhe são atribuídos, além das mudanças corporais advindas da gestação e a confusão de sentimentos. Para algumas mulheres o retorno a vida sexual é marcado por desafios, compreendendo todas as mudanças que sofreu no período gestacional, bem como no período puerperal. Diante dos discursos pode-se observar que as mulheres sentem que seus parceiros e familiares a esquecem e destacase o quanto é fundamental o cuidado psicológico com a mulher/mãe, entendendo que se a mesma estiver em boas condições emocionais conseguirá exercer com autonomia os cuidados ao filho que acaba de chegar.

Nesta perspectiva entende-se que as mulheres deveriam participar de grupos e rodas de conversa que visem fortalecê-las psicologicamente para compreender o processo pelo qual está passando e pelo que ainda chegará que é o período puerperal. Desta forma faz-se necessário profissionais engajados a efetivar as medidas de saúde pública, dedicando-se a compreender a mulher em sua totalidade, na tentativa de entender os aspectos psicológicos que a envolvem para que com isso consigam exercer suas funções maternas em plenitude, não à mercê da sociedade. Pode-se destacar também que a pesquisa pôde trazer benefícios para a mulher/mãe, uma vez que abriu espaço para essas mulheres se perceberem e relatarem sobre suas experiências.

\section{Referências}

Aching, M. C., Biffi, M., \& Granato, T. M. M. (2016). Mães de primeira viagem: narrativas de mulheres em situação de vulnerabilidade social, 21(2), 235-244. Doi: $<\underline{\text { https://doi.org/10.4025/psicolestud.v21i2.27820> }}$ 
Andrade, C. (2016). A construção da Identidade, Auto-conceito e Autonomia em Adultos Emergentes. Psicologia Escolar e Educacional, 20(1), 137-146. Doi: $<$ http://dx.doi.org/10.1590/2175-3539/2015/0201944>

Andrade, C. de J., Baccelli, M.S., \& Benincasa, M. (2017). O vínculo mãe-bebê no período de puerpério: uma análise Winnicottiana. Revista do NESME 14(1), 1-13, Disponível em: $<$ http://pepsic.bvsalud.org/pdf/vinculo/v14n1/v14n1a04.pdf $>$ Acesso em: $26 / 11 / 2019$

Badinter, E. (2011). O conflito: a mulher e a mãe. (V. L. Reis, Trad.). Rio de Janeiro: Record.

Beebe, K., Davis, A., \& Gleadle, K. (2015). Space, place and gendered identities: feminist history and the spatial turn. New York: Routledge.

Bion, W. R. (1994). Estudos psicanalíticos revisados. Tradução: Wellington M. de Melo Dantas. 3. ed. Rio de Janeiro: Imago.

Brasil. Ministério da Saúde. (2003). Parto, aborto e puerpério: assistência humanizada à saúde. Brasília/Brasil.

Camargo, B. V., \& Justo, A. M. (2015). IRaMuTeQ: um software gratuito para análise de dados textuais. Temas em Psicologia, 21(2), 513-518. Doi: $<$ https://dx.doi.org/10.9788/TP2013.2-16 $>$.

Chartier, J. F., \& Meunier, J. G. (2011). Text mining methods for social representation analysis in Large Corpora. Papers on Social Representations, 20(37),1-47. Disponível em: <http://psr.iscte-iul.pt/index.php/PSR/article/view/452>. Acesso em: $30 \mathrm{de}$ outubro de 2019.

Coutinho, S., \& Menandro, P. (2015). Representações sociais do ser mulher no contexto familiar: um estudo intergeracional. Psicologia e Saber Social, 4(1), 52-71. Disponível em: $<$ https://www.e-publicacoes.uerj.br/index.php/psisabersocial/article/view/13538> Acesso em: 30/10/2019.

Cuevas, A. C., \& Renninson, C. M. (Eds.). (2016). The wiley Handbook on the Psycology of violence. ( $5^{\mathrm{a}}$ edição, pp.86 -99). Malden, MA, USA: Wiley Blackwell. Doi: $<\underline{\text { https://doi.org/10.1002/9781118303092.fmatter }>}$

Estrela, J. M., Machado, M. da S., \& Castro, A. (2016). O ser mãe: representações sociais do papel materno de gestantes e puérperas. Revista Multidisciplinar e de Psicologia. 12(42), $569 \quad-578 . \quad$ Disponível em:

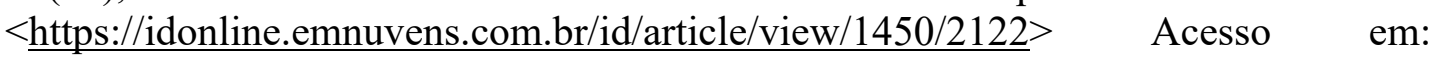
30/10/2019.

Figueiredo, L. C. (2009). As diversas faces do cuidar: considerações sobre a clínica e a cultura. In: MAIA, M.S. (Org.). Por uma ética do cuidado. (pp. 225-250). Rio de Janeiro: Garamond. 
Gil, A. C. (2017). Como elaborar projetos de pesquisa. São Paulo: Atlas Editora.

Giaretta, D. G., \& Fagundez, F. (2015). Aspectos psicológicos do puerpério: uma revisão. Psicologia, Portal dos Psicólogos, 1-8. Disponível em: $<$ http://www.psicologia.pt/artigos/textos/A0922.pdf $>$. Acesso em: 30/10/2019.

Giordani, R. C., Formighieri, P. D., Bezerra, I., \& Almeida, C. C. B. (2018). Maternidade e amamentação: identidade, corpo e gênero. Ciência \& Saúde Coletiva, 23(8), 27312739. Doi: < http://dx.doi.org/10.1590/1413-81232018238.14612016>

Greinert, B.R. M., \& Milani, R. G. (2015). Depressão pós-parto: uma compreensão psicossocial. Psicologia: teoria e prática, 17(1), 26-36. Disponível em: < http://pepsic.bvsalud.org/pdf/ptp/v17n1/03.pdf $>$ Acesso em: 30/10/2019.

Jerusalinsky, J. (2009). A maternidade e o Gozo fálico. In A criação da criança: letra e gozo nos primórdios do psiquismo (pp. 122-134). Tese de Doutorado, Pontifícia Universidade Católica de São Paulo, São Paulo.

Leite, M. G., Rodrigues, D. P., Sousa, A. A. S. de, Melo, L. P. T. de, \& Fialho, A. V. de M. (2014). Sentimentos advindos da maternidade: Revelação de um grupo de gestantes. Psicologia em Estudo, 19(1), 115-124. Doi: $<\underline{\text { http://dx.doi.org/10.1590/1413-7372217650011 > }}$

Lopes, R. C. S., Alfaya, C., Machado, C. V., \& Piccinini, C. A. (2005). "No início eu saía com o coração partido...": As primeiras situações de separação mãe-bebê. Revista Brasileira Crescimento Desenvolvimento Humano, 15(3), 26-35.

Maldonado M. T. (2017). Psicologia da gravidez: Gestando pessoas para uma sociedade melhor: Rio de Janeiro: Ideias \& Letras.

Mestieri, L. H. M., Meneguette, R. I., \& Meneguette, C. (2005). Estado puerperal. Revista da Faculdade de Ciências Médicas de Sorocaba 7(1), 5-10. Disponível em: https://revistas.pucsp.br/RFCMS/article/view/359 Acesso em: 30/10/2019.

Merighi, M. A. B., Gonçalves, R., \& Rodrigues, I. G. (2006). Vivenciando o período puerperal: uma abordagem compreensiva da Fenomenologia Social. Revista Brasileira de Enfermagem, 59(6), 775-779. Doi: < $\underline{71672006000600010>}$

Mozzaquatro, C. de O., Arpini, D. M., \& Polli, R. G. (2015). Relação mãe-bebê e promoção de saúde no desenvolvimento infantil. Psicologia em Revista, 21(2), 334351. Doi: $<$ https://doi.org/10.5752/P.1678-9523.2015V21N2P333>

Ngai F. W., \& Ngu S. F. (2013). Quality of life during the transition to parenthood in Hong Kong: a longitudinal study. Journal of Psychosomatic Obstetrics \&

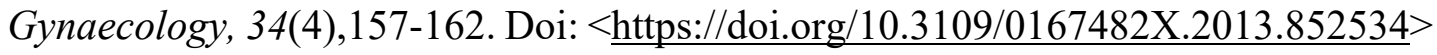

Piccinini, C. A., Gomes, A., Nardi, T., \& Lopes, R.S (2008). Gestação e a Constituição da Maternidade. Psicologia em Estudos, 13(1), 63-72. 
Primo, C. C., Dutra, P. R., Lima, E. F. A., Alvarenga, S. C., \& Leite, F. M. C. (2015). Redes sociais que apoiam a mulher durante a amamentação. Cogitare Enfermagem, 20(2), 426-433. Disponível em: $<$ https://revistas.ufpr.br/cogitare/article/view/37453/25554> Acesso em: 30/10/2019.

Sarti, C. A. (2003). A família como ordem simbólica. Psicologia USP, 15(3), 11- 28. Disponível em: < http://www.scielo.br/pdf/pusp/v15n3/24603.pdf> Acesso em: 30/10/2019.

Tajfel, H. (1978). Differentiation between social groups: studies in the social psychology of intergroup relations. San Diego: Academic Press.

Taylor, U. Y. (1998). Making waves: The theory and practice of Black feminism. The Black Scholar, 28(2), 18-28. Doi: https://doi.org/10.1080/00064246.1998.11430912

Teixeira M. A., Nitschke R. G., \& Silva, L. W. S. (2011). A prática da amamentação no cotidiano familiar - um contexto intergeracional: influência das mulheres-avós. Revista Temática Kairós Gerontologia, 14(3), 205-221. Disponível em: $<$ https://revistas.pucsp.br/kairos/article/viewFile/6501/4713 > Acesso em: 30/10/2019.

Zanatta, E. P., Rossato, C. R., \& Alves, A. P. (2017). A experiência da maternidade pela primeira vez: as mudanças vivenciadas no tornar-se mãe. Pesquisas e Práticas Psicossociais, 12(3), 1-16. Disponível em: $<$ http://pepsic.bvsalud.org/pdf/ppp/v13n1/05.pdf $>$ Acesso em: 30/10/2019. 